\title{
LINFOMA ESPONTÂNEO EM CAMUNDONGO Mus musculus - RELATO DE CASO
}

(Spontaneous lymphoma in mouse Mus musculus - Case Report)

Carolina Fontana, Arthur Colombari Cheng, Juliana das Chagas Goulart, Karim Cristhine Pase Montagnin, Joana Cristina Smaha de Jesus Lima, Carolina Fucks de Souza, Ronaldo José Piccoli, Aline de Marco Viott

Universidade Federal do Paraná, Palotina, Paraná, Brasil.

${ }^{*}$ Correspondência: carolinavetfontana@gmail.com

RESUMO: Os linfomas são neoplasias de origem hematopoiética originados a partir da proliferação de linfócitos. A formação destas neoplasias se dá principalmente em baço, linfonodos e fígado, entretanto podem se desenvolver em qualquer órgão devido as concentrações de linfócitos circulantes. Na Medicina Veterinária, são classificados quanto a sua distribuição anatômica, morfologia celular e organização histológica (MORRIS \& DOBSON,2001). Tumores hematopoiéticos estão entre as grandes causas de mortalidade e morbidade em animais de laboratório, sendo observados em camundongos de quase todas as linhagens, principalmente nas consanguíneas. Dentre os linfomas espontâneos em camundongos, a forma mais relatada é o Linfoma de Células B Folicular, envolvendo principalmente o baço, placas de Peyer e linfonodos mesentéricos (PERCY \& BARTHOLD, 2007). Relata-se os aspectos clínicos, macroscópicos e microscópicos de um caso de linfoma espontâneo em camundongo (Mus musculus) diagnosticado pelo Laboratório de Patologia Veterinária (LPV) da Universidade Federal do Paraná (UFPR), Setor Palotina. Foi atendido no Hospital Veterinário da UFPR, Setor Palotina, um camundongo, fêmea, de um ano de idade apresentando dispneia e aumento de volume abdominal, após a avaliação física o paciente foi encaminhado para avaliação ultrassonográfica evidenciando deposito de gordura abdominal abundante e enterite. Após a liberação do paciente, o mesmo evoluiu para óbito sendo encaminhado para necropsia no LPV. Macroscopicamente, observou-se mucosas oculares pálidas, acentuada esplenomegalia, fígado difusa e acentuadamente amarelado, pulmão inflado moderadamente hiperêmico além de linfoadenomegalia de linfonodo mesentérico. Na avaliação histológica dos tecidos hepático, esplênico, pulmonar, renal, ovariano, cardíaco e de linfonodo mesentérico havia áreas de proliferação neoplásica de células redondas, altamente celular, mal demarcada, não encapsulada e infiltrativa. As células eram arranjadas em mantos de células bem agrupadas sobre estroma fibrovascular escasso. As mesmas eram arredondadas a poligonais com limites celulares distintos; o citoplasma era escasso, basofílico, homogêneo; o núcleo redondo, paracentral, cromatina frouxa e com um a dois nucléolos evidentes, por vezes o núcleo era irregular, com aspecto multilobular e cromatina condensada (flower cells). Havia anisocitose e anisocariose acentuada e oito mitoses por campo de grade aumento. Notou-se moderada quantidade das células neoplásicas nos vasos sanguíneos (êmbolos neoplásicos). Os achados histopatológicos associados as alterações clínicas do paciente foram compatíveis com o diagnóstico de linfoma, sugerindo-se linfoma de grandes células B do mediastino ou linfoma anaplasico em decorrência da presença de flower cells. A ausência de massa mediastinal sugere o diagnóstico de linfoma anaplasico. Destaca-se a importância da inclusão do linfoma para diferencial de aumento de volume em camundongos adultos, tendo em vista que uma investigação minuciosa possibilita um tratamento adequado. É de grande importância ressaltar que é necessário a avaliação histopatológica e imunohistoquimica para o diagnóstico definitivo.

Palavras-chave: oncopatologia, roedores, linfossarcoma.

\section{Referências}

MORRIS, J and DOBSON, J. Small Animal Oncology. $1^{\circ}$ ed, Blackwell Publishing, 2001

PERCY, D. H and BARTHOLD S.W, Pathology of Laboratory Rodents and Rabbits. $3^{\mathrm{a}}$ ed, Blackwell Publishing, 2007. 